\title{
A New Planar Multiband Antenna for GPS, ISM and WiMAX Applications
}

\author{
I. Zahraoui ${ }^{1}$, A. Errkik ${ }^{2}$, M. C. Abounaima ${ }^{3}$, A. Tajmouati ${ }^{4}$, L. E. Abdellaoui ${ }^{5}$, M. Latrach $^{6}$ \\ ${ }_{1,2,4,5}$ LMEET Laboratory FST of Settat Hassan 1st University, Morocco \\ ${ }^{3}$ LSIA Laboratory FST of Fes Sidi Mohamed Ben Abdellah University, Morocco \\ ${ }^{6}$ Microwave group, ESEO angers, France
}

\begin{tabular}{l} 
Article Info \\
\hline Article history: \\
Received Jan 6, 2017 \\
Revised Mar 10, 2017 \\
Accepted Mar 24, 2017 \\
\hline
\end{tabular}

\section{Keyword:}

GPS band

ISM band

Modified Ground Structure

Multibande Antenna

WiMAX band

\begin{abstract}
In this paper a design of a new antenna with modified ground plane is validated for multiband applications. The proposed modified ground structure is incorporated with a patch antenna to boost the performance. The antenna's entire area is $59.5 \times 47 \mathrm{~mm}^{2}$ and is printed on an FR-4 substrate and fed by a $50 \mathrm{Ohm}$ microstrip line. This structure is validated in the GPS $(1.56-1.58 \mathrm{GHz})$ band at $1.57 \mathrm{GHz}$, in the ISM $(2.43-2.49 \mathrm{GHz})$ band at $2.45 \mathrm{GHz}$ and in the WiMAX $(3.50-3.56 \mathrm{GHz})$ band at $3.53 \mathrm{GHz}$. These three frequency bands have good matching input impedance for, $\mathrm{S} 11 \leq-10 \mathrm{~dB}$. The antenna presents a good performance in terms of radiation pattern, and it is designed, optimized, and miniaturized by using CST-MW whose results are compared with other solvers HFSS and ADS. The results obtained by the use of the three EM solvers are in good agreement. After realization, we have tested and validated this antenna. The measurement results of the antenna present a good agreement with the numerical results.
\end{abstract}

Copyright $(0) 2017$ Institute of Advanced Engineering and Science. All rights reserved.

\section{Corresponding Author:}

I. Zahraoui,

Departement of physics,

LMEET laboratory FST of Settat Hassan $1^{\text {st }}$ University,

Settat, Marocco.

Email: zahraoui.issam84@gmail.com

\section{INTRODUCTION}

These days, several researchers have dedicated large efforts to the development of antennas that meet the needs of the wireless communication industry that requires better performance, particularly in term of multiband operations and miniaturization. In fact, the design and development of a single antenna working in two or more frequency bands, such as in Global System for Mobile Communications (GSM), Digital Communication System (DCS), Global Positioning System (GPS), wireless local area network (WLAN) or Wifi and worldwide interoperability for microwave access (WiMAX) is generally not an easy task. The IEEE 802.11 WLAN standard allocates the license-free spectrum of $2.4 \mathrm{GHz}(2.40-2.48 \mathrm{GHz}), 5.2 \mathrm{GHz}$ (5.15-5.35 GHz) and 5.8 GHz (5.725-5.825 GHz). WiMAX, based on the IEEE802.16 standard, has been evaluated by companies for last mile connectivity, which can reach a theoretical up to 30 mile radius coverage. The WiMAX forum has published three license spectrum profiles, namely the $2.5 \mathrm{GHz}$ $(2.495-2.69 \mathrm{GHz}), 3.5 \mathrm{GHz}(3.5-3.6 \mathrm{GHz})$ and $5.5(5.25-5.850 \mathrm{GHz})$ varying from country to country [1-7]. Recently, the microstrip patch antenna has been introduced with the aim of improving performance and obtaining the multiband behavior. This technology offers many advantages such as low weight, low profile planar configuration, low fabrication costs and the ability to integrate with microwave integrated circuits technology. Therefore, the microstrip patch antenna is very well-suited for applications such as wireless communications system, cellular phones, radar systems, and satellite communications systems [8-13]. 
There are several techniques which can be used with microstrip patch antenna to achieve the multiband behavior. Among these, we can find higher order resonances, resonant traps, combined resonant structures and parasitic resonators [14]. We can also use the modified ground structure to miniaturize and improve the bandwidth and reflection coefficient for multiband antennas [15-18].

In this paper, we have used and developed a new microstrip patch antenna with a modified ground structure. The proposed antenna has been optimized and tuned to operate with the following bands of GPS $(1.176 \mathrm{GHz} / 1.227 \mathrm{GHz} / 1.57 \mathrm{GHz})$, ISM $(2.45 \mathrm{GHz})$ and WiMAX $(2.5 \mathrm{GHz} / 3.5 \mathrm{GHz} / 5.5 \mathrm{GHz})$, and it was initially designed and simulated by using CST microwave studio and verified with other electromagnetic solvers ADS and HFSS, then fabricated to confirm the simulation results.

\section{ANTENNA DESIGN}

The geometry of the proposed antenna which is shown in Figure 1 is printed on a low cost FR-4 substrate with a total area of $59.5 \times 47 \mathrm{~mm}^{2}\left(\mathrm{~L}_{\text {sub }} \times \mathrm{W}_{\text {sub }}\right)$, and a dielectric constant $\varepsilon \mathrm{r}=4.4$, a thickness $\mathrm{h}=1.6$ $\mathrm{mm}$, a loss tangent tan $(\delta)=0.025$ and a metallization thickness of $\mathrm{t}=0.035 \mathrm{~mm}$. The microstrip antenna is fed by a microstrip line with $50 \Omega$ characteristic impedance. The dimensions of the antenna are optimized and miniaturized by using CST-MW. The optimization dimension of the parameters of the proposed antenna are illustrated in Table 1.

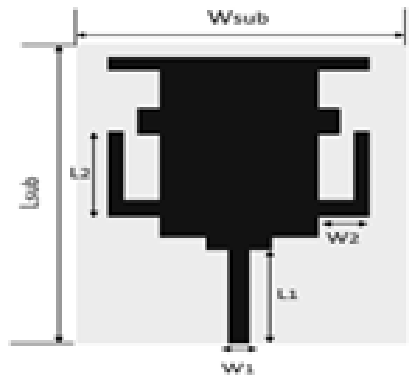

(a)

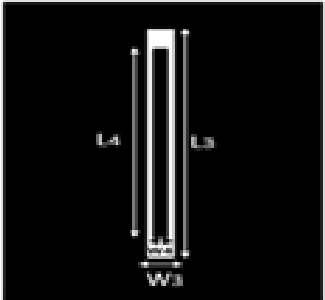

(b)

Figure 1. Geometry of the proposed antenna (a) front view (b) back view

Table 1. Dimension of the proposed antenna (unit:mm)

\begin{tabular}{cccc}
\hline Parameters & Values & Parameters & Values \\
\hline $\mathrm{W}_{\text {sub }}$ & 47 & $\mathrm{~L}_{\text {sub }}$ & 59.5 \\
$\mathrm{~W} 1$ & 3 & $\mathrm{~L} 1$ & 19 \\
$\mathrm{~W} 2$ & 7 & $\mathrm{~L} 2$ & 16.5 \\
$\mathrm{~W} 3$ & 4 & $\mathrm{~L} 3$ & 45 \\
$\mathrm{~L} 4$ & 37 & $\mathrm{~W} 4$ & 2 \\
\hline
\end{tabular}

The purpose of this study is to design a novel compact antenna structure for three bands applications. The design procedure of this antenna is as follow. Firstly, the rectangular patch antenna as shown in Figure 2 is calculated from the following Equations [19]:

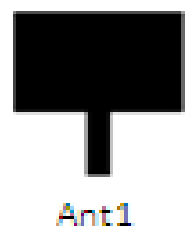

Figure 2. Microstrip patch antenna structure

The Width of the rectangular patch is given by: 
$W=\frac{1}{2 f_{r} \sqrt{\mu_{0} \varepsilon_{0}}} \sqrt{\frac{2}{\varepsilon_{r}+1}}=\frac{c}{2 f_{r}} \sqrt{\frac{2}{\varepsilon_{r}+1}}$

The expression of the effective length constant is given by:

$$
\varepsilon_{\text {eff }}=\frac{\varepsilon_{r}+1}{2}+\frac{\varepsilon_{r}-1}{2}\left[1+12 \frac{h}{W}\right]^{-\frac{1}{2}}
$$

The length extension is given by:

$$
\Delta L=0.412 * h * \frac{\left(\varepsilon_{e f f}+0.3\right)\left(\frac{W}{h}+0.264\right)}{\left(\varepsilon_{e f f}-0.258\right)\left(\frac{W}{h}+0.8\right)}
$$

The length of rectangular patch is given by:

$$
L=L_{e f f}-2 \Delta L=\frac{c}{2 f_{r} \sqrt{\varepsilon_{e f f}}}-2 \Delta L
$$

Where: $\mathrm{c}$ is the free space velocity of light, $\mathrm{cr}$ is the relative permittivity of substrate, $\mathrm{L}$ is the length of patch, $\mathrm{W}$ is the width of the patch, $\mathrm{h}$ is the height of the substrate, eeff is the effective relative permittivity of patch, Leff is the effective length of the patch and fr is the resonant frequency.

The obtained parameters of rectangular microstrip patch antenna are $\mathrm{L}=28.24 \mathrm{~mm}, \mathrm{~W}=36.51 \mathrm{~mm}$ which is validated at $\mathrm{fr}=2.5 \mathrm{GHz}$.

Secondly, we have modified the structure presented in Figure 3 in order to obtain multiband behavior. An L-shaped arm and a tiny rectangle are put in symmetrically on both sides of the patch antenna, and a rectangular-shaped arm is placed on the upper part of the microstrip patch antenna. We notice the emergennce of new resonant frequencies as shown in Figure 4. The appearance of these resonant frequencies is calculated by using Equations (5) and (6) [20].

$$
\begin{aligned}
& f_{i}=\frac{c}{\lambda_{g} \cdot \sqrt{\varepsilon_{e f f}}} \text { where } l_{j}=\frac{\lambda_{g}}{4} \\
& \sqrt{\varepsilon_{\text {eff }}} \approx \frac{\varepsilon_{r}+1}{2}
\end{aligned}
$$

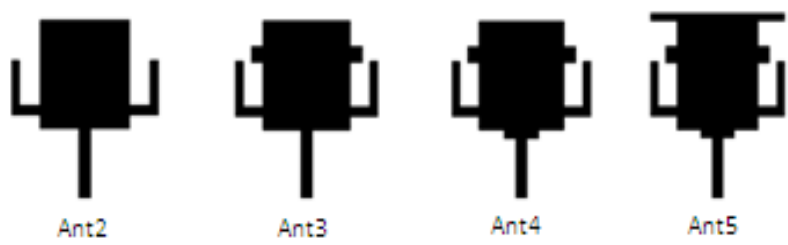

Figure 3. Evolution of the microstrip patch antenna

After designing the antenna as depicted in Figure 2 and Figure 3, we have obtained reflection coefficient corresponding to each antenna from 1 to 5 as shown in Figure 4. 


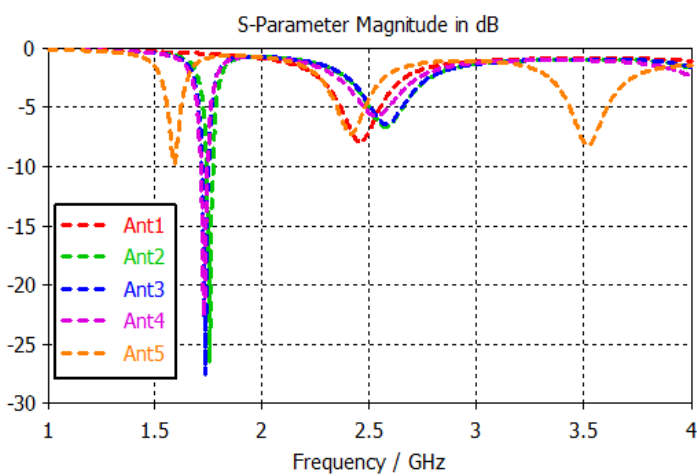

Figure 4. Reflection coefficient versus frequency with of the different modified ground structure

As a last part of the design procedure, a modified ground structure, consisting of two rectangles of different size etched in the ground, is introduced in order to enhance the reflection coefficient as shown in Figure 5. As depicted in Figure 6, the introduction of the second modified ground structure permits to have a good matching of the input impedance. Table 2 shows the simulation results brought about by the modification of the ground plane.

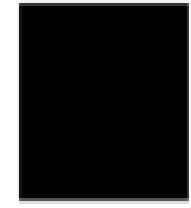

Ant:_Without mocified Eround atructur

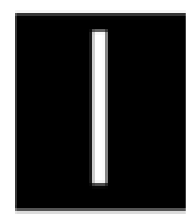

$$
\text { Ants_With first }
$$
modified ground atructure

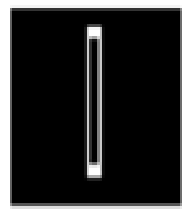

Ants_with second modif ed ground structure

Figure 5. Evolution of the modified ground structure

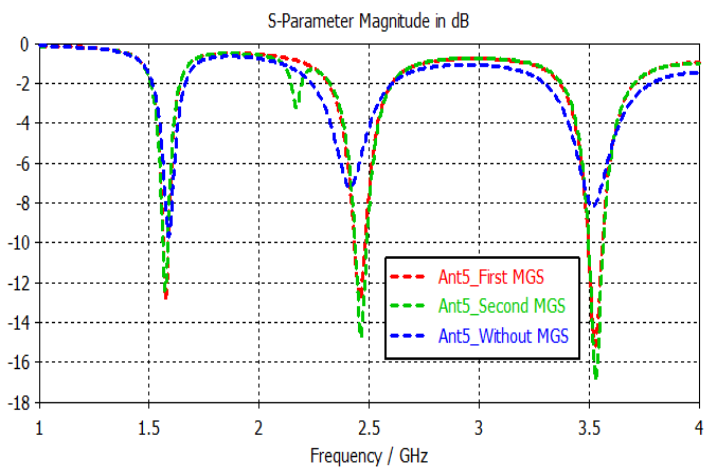

Figure 6. Reflection coefficient versus frequency with of the different modified ground structure

Table 2. Simulation results related to the changes of the ground plane

\begin{tabular}{|c|c|c|c|}
\hline Evolution without and with & \multicolumn{2}{|c|}{$\mathrm{S} 11 \leq-10 \mathrm{~dB}$} & $\mathrm{BP} \leq-10 \mathrm{~dB}$ \\
\hline Ant5_Without Modified ground & \multicolumn{2}{|c|}{--} & -- \\
\hline \multirow[t]{3}{*}{ Ant5_First Modified Ground } & First resonance & $1.57 \mathrm{Ghz}$ & $1.56-1.58 \mathrm{Ghz}$ \\
\hline & Second resonance & $2.45 \mathrm{Ghz}$ & $2.43-2.48 \mathrm{Ghz}$ \\
\hline & Third resonance & $3.52 \mathrm{Ghz}$ & $3.49-3.56 \mathrm{Ghz}$ \\
\hline \multirow{3}{*}{ Ant5_Second Modified Ground } & First resonance & $1.56 \mathrm{Ghz}$ & $1.55-1.58 \mathrm{Ghz}$ \\
\hline & Second resonance & $2.45 \mathrm{Ghz}$ & 2.43-2.49 Ghz \\
\hline & Third resonance & $3.53 \mathrm{Ghz}$ & $3.50-3.56 \mathrm{Ghz}$ \\
\hline
\end{tabular}


As depicted in Figure 7, we have obtained an optimized antenna with the first resonant frequency of $1.56 \mathrm{GHz}$ and a bandwidth $(1.55-1.58 \mathrm{GHz})$, that can be suitable to the GPS band and the second resonant occurs at $2.45 \mathrm{GHz}$ with a bandwidth (2.43-2.49 GHz), that covers the ISM band, and the third resonant occurs at $3.53 \mathrm{GHz}$ with a bandwidth $(3.50-3.56 \mathrm{GHz})$, that covers the WiMAX band.

Another way to verify the different performances of the proposed antenna is the use of other electromagnetic solvers HFSS and ADS. As shown in Figure 8, we can conclude that there is a good agreement between these three solvers.

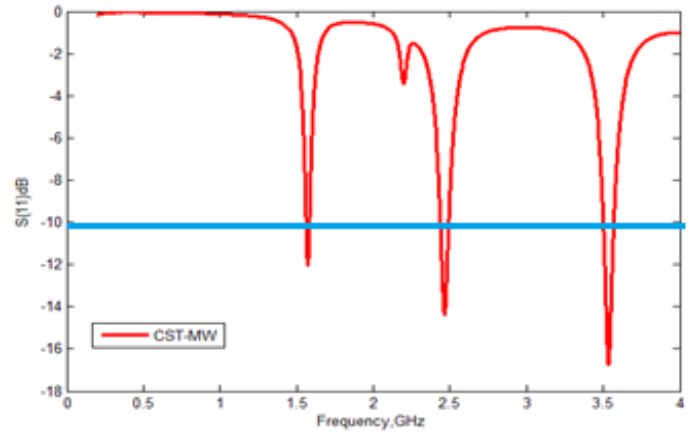

Figure 7. Final reflection coefficient versus frequency

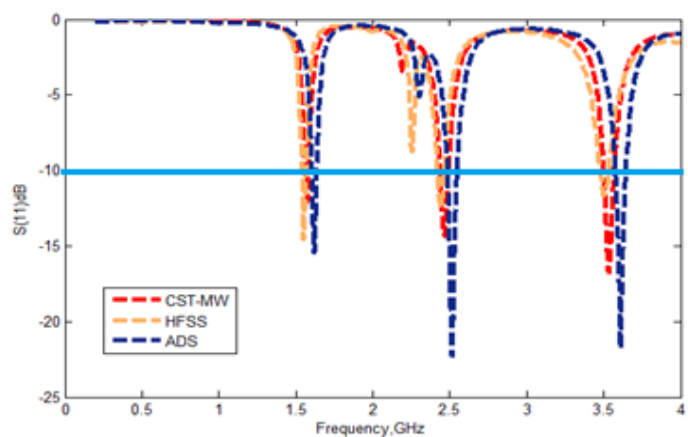

Figure 8. Comparison of reflection coefficient $|\mathrm{S} 11|$ between CST-MW, HFSS and ADS

In order to better understand the antenna behavior, the current distributions of the three bands antenna at resonants frequencies of 1.56, 2.45 and $3.53 \mathrm{GHz}$ are simulated and shown respectively in Figure 9(a) and 9(c).

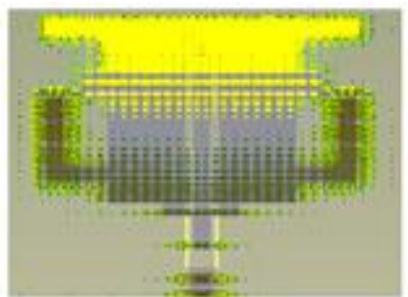

(a)

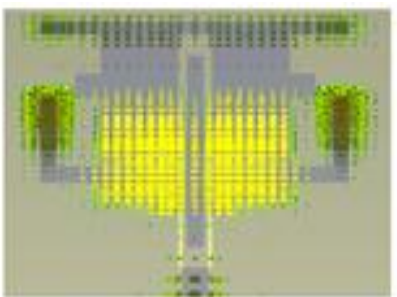

(b)

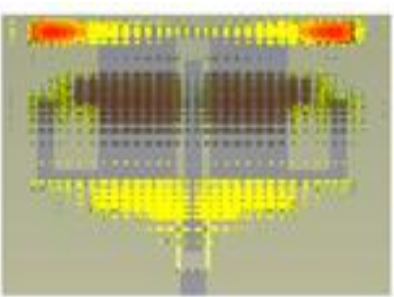

(c)

Figure 9. Current distributions of the proposed antenna at: a: @ $1.56 \mathrm{GHz}$ b: @ $2.45 \mathrm{GHz}$ c: @ $3.53 \mathrm{GHz}$

As we can see from Figure 9. Current distribution affects different parts of the patch depending on the frequency band. When the frequency reaches $1.56 \mathrm{GHz}$, the current distribution is heavily concentrated in the upper part of the microstrip patch antenna. When the frequency reaches $2.45 \mathrm{GHz}$, the density of the current distribution is concentrated in the lower part of the microstrip antenna and on the upper parts of the L-shaped arms. When the frequency is $3.53 \mathrm{GHz}$, the current distribution is concentrated along the rectangular shape which is placed on the upper part of the microstrip patch antenna and the lower part of the microstrip patch antenna.

The simulated Far-field radiation patterns in CST-MW for the three resonant frequencies are shown in Figure 10. It can be seen that the antenna presents a stable radiation and a quasi-omnidirectional radiation pattern for the resonant frequency bands for each resonant frequency. 


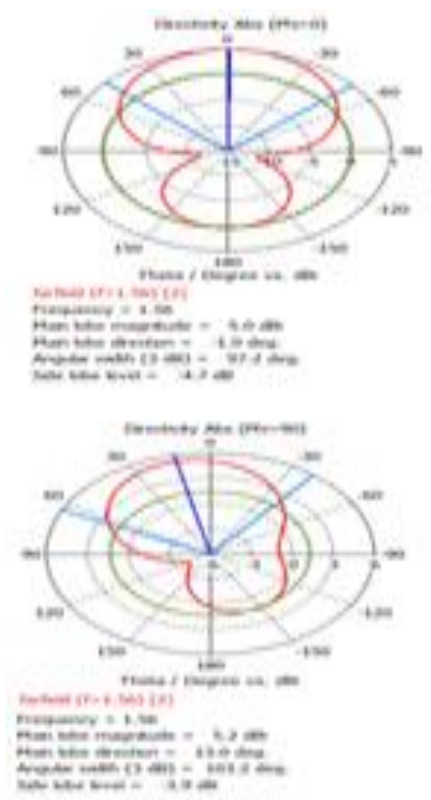

$(a)$
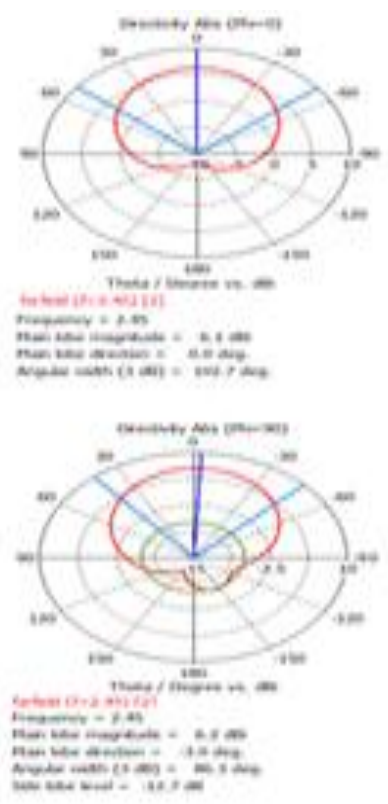

(b)
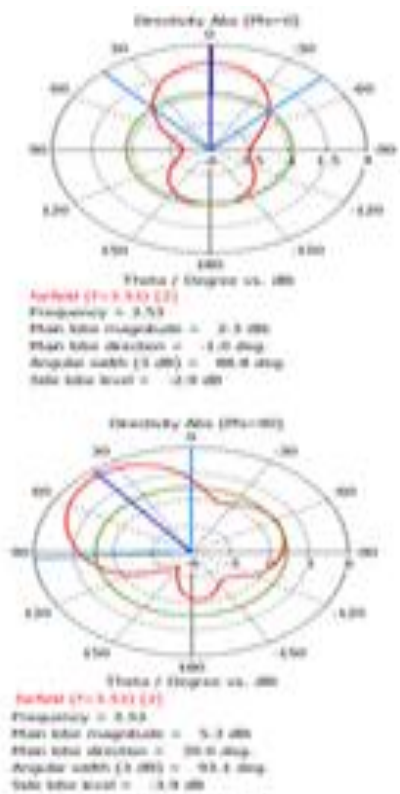

(c)

Figure 10. Radiation pattern of the proposed antenna (a) @ $1.56 \mathrm{GHz}$, (b) @ 2.45 (c) @ $3.53 \mathrm{GHz}$

From Figure 11, we notice that the VSWR is less than 2 at the frequency range of $(1.558-1.588 \mathrm{GHz})$, $(2.434-2.501 \mathrm{GHz})$ and $(3.498-3.572 \mathrm{GHz})$.

Figure 12 presents the variation of the gain versus frequency. After the simulation, we have obtained the gain $2.123 \mathrm{~dB}$ at $1.56 \mathrm{GHz}, 3.355 \mathrm{~dB}$ at $2.45 \mathrm{GHz}$ and $2.299 \mathrm{~dB}$ at $3.53 \mathrm{GHz}$.

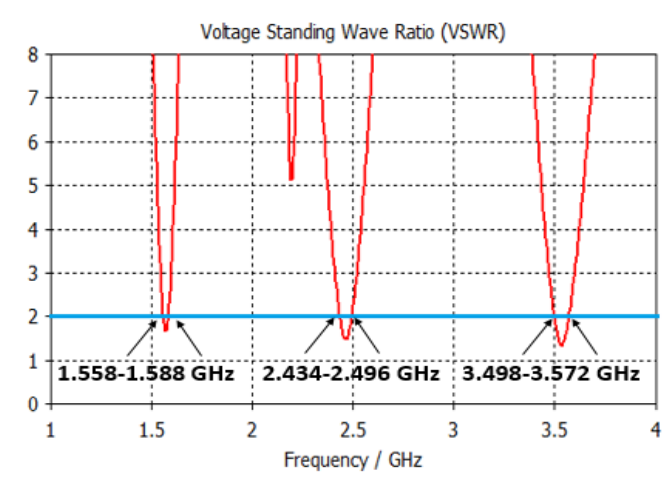

Figure 11. VSWR versus frequency

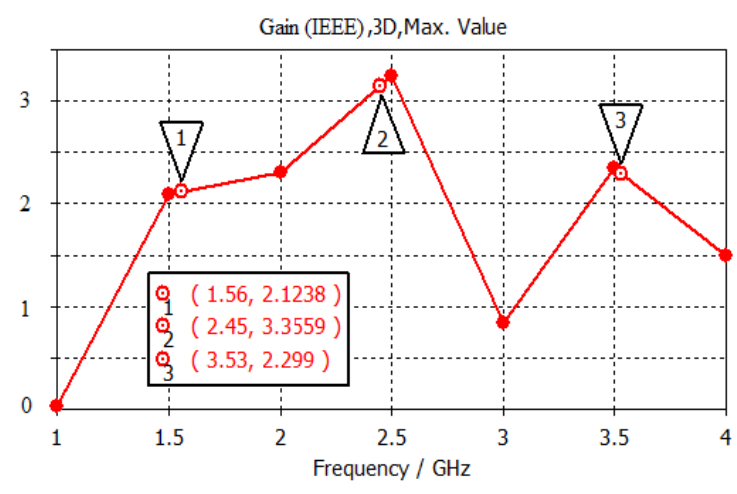

Figure 12. Gain versus frequency

Table 3 presents a comparison of the proposed antenna with bibliography regarding antenna size, resonance frequency and antenna purpose. As we can see from the same table that the proposed antenna is smaller in terms of size and suitable for tri-band applications.

Table 3. Comparison of proposed antenna performance with other compact antennas

\begin{tabular}{cccc}
\hline $\begin{array}{c}\text { Published literature versus } \\
\text { proposed work }\end{array}$ & $\begin{array}{c}\text { Antenna Size } \\
\left(\mathrm{mm}^{2}\right)\end{array}$ & $\begin{array}{c}\text { Resonance Frequency } \\
(\mathrm{Ghz})\end{array}$ & Antenna purpose \\
\hline Ref[21] & $75 \times 75$ & $2.4 / 5.2$ & Dual-Band \\
$\operatorname{Ref}[22]$ & $50 \times 75$ & $2.4 / 5.2$ & Dual-band \\
Ref[23] & $100 \times 45$ & $2.4 / 3.5 / 5.2$ & Tri-band \\
Proposed work & $59.5 \times 75$ & $1.56 / 2.45 / 3.53$ & Tri-band \\
\hline
\end{tabular}




\section{EXPERIMENTAL RESULTS AND DISCUSSION}

After the design and optimization of the multi-band antenna by using CST-MW, the prototype of the investigated antenna is achieved and measured. Figure 12 presents a photograph of the fabricated multiband antenna, the proposed circuit is fabricated on an FR-4 substrate.
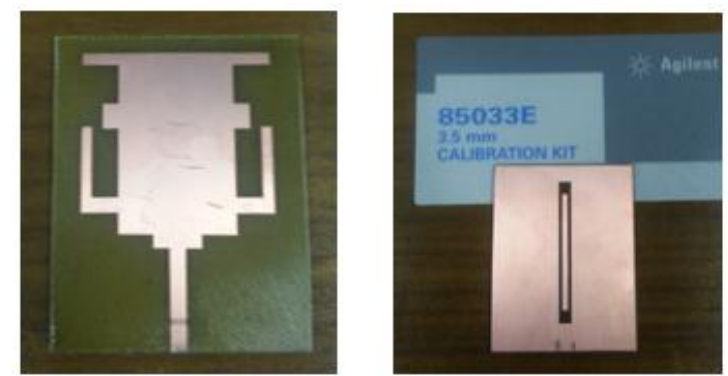

Figure 12. Photo of the fabricated antenna structure (a) Top face (b) Back face

The achieved antenna is tested by using a VNA from Agilent Technologies. The calibration Kit used is a $3.5 \mathrm{~mm}$ from Agilent technologies. After taking into account the losses in cable used for the test, we have conducted comparison between simulation and measurement results as presented in Figure 13.

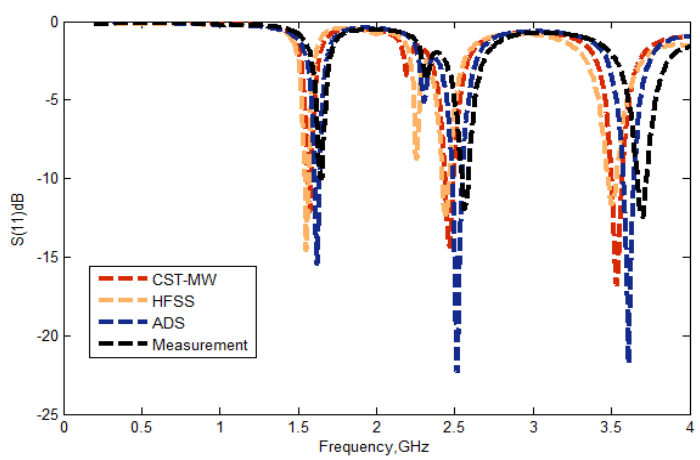

Figure 13. Comparison of simulated and measured at the level of reflection coefficient

As we can see in Figure 13 there is a good agreement between the simulation and the measurement albeit a slight difference. This is due to the fabrication constraints, uncertainties in the dielectric constant and substrate thickness and soldering effects.

\section{CONCLUSION}

In this work, we have carried out the design of a microstrip patch antenna with a modified ground structure. This antenna has been designed and optimized by using CST-MW and verified by other solvers HFSS and ADS. The achieved and tested microstrip patch antenna with modified ground structure presents a good agreement between simulation and measurement results. The measurement results allow us to validate a new multiband antenna structure for GPS $(1.56-1.58 \mathrm{GHz})$, ISM $(3.50-3.56 \mathrm{GHz})$ and WiMAX $(3.50-3.56$ $\mathrm{GHz}$ ) frequency bands with a compact size of $59.5 \times 47 \mathrm{~mm}^{2}$. The antenna is compact, lightweight, low cost, simple to fabricate and easy to integrate with microwave printed devices.

\section{ACKNOWLEDGEMENTS}

We would like to thank Mr. Angel Mediavilla Sanchez Director of DICOM Laboratory in Spain, for allowing us to perform simulations by using electromagnetic solvers and to use many instruments for measurement. 


\section{REFERENCES}

[1] S. Manafi, S. Nikmehr, M. Bemani, "A Planar Reconfigurable Multfunctional Antenna For WLAN/WIMAX/UWB/PCS-DCS/UMTS Applications", Progress In Electromagnetics Research C, vol. 26, pp. 123-137, 2012.

[2] Y.-Q. Zhang, X. Li, L. Yang, S.-X. Gong, "Dual-band Circularly Polarized Antenna with low wide-angle axialratio for tri-band GPS Application", Progress in Electromagnetics Research C, vol. 32, pp.169-179, 2012.

[3] I. Zahraoui, A. Errkik, E. Abdelmounim, H. Bennis, L. E. Abdellaoui, A. M. Sanchez, "A New Design of a CPW Fed Triple-Band for GPS, UMTS and WiMAX Applications", International Journal on Communications Antenna and Propagation (I.Re.C.A.P.), vol. 5, 2015.

[4] Y. -L. Kuo, K. -L. Wong, "Printed double-T monopole Antenna for 2.4/5.2 GHz dual-band WLAN Operations", IEEE Trans. Antennas Propagation, Vol. 51, pp. 2187-2192, Sept 2003.

[5] J. Zhong, R. M. Edwards, L. Ma, X. Sun, "Multiband slot Antenna for metal back cover mobile handsets", Progress in Electromagnetics Letters, vol. 39, pp. 115-126, 2013.

[6] X. Zheng, D. Zhengwei, "A Novel Wideband Antenna for UMTS and WlAN bands Employing a Z-shaped Slot and Folded T-shaped ground Branch to widen Bandwidth", IEEE Antennas and Wireless Propagation Letters, pp. 1-4, 2008.

[7] H.-W. Liu, C.-H. Ku, C. -F. Yang, "Novel CPW-fed Planar Monopole Antenna for WiMAX/WLAN Applications", IEEE Antennas and Wireless Propagation Letter, vol.9, pp. 240-243, 2010.

[8] J.-H. Lu, Y.-H. Li, "Planar Multi-Band T-Shaped Monopole Antenna With A Pair Mirrored L-Shaped Strips For WLAN/WiMAX operation”, Progress In Electromagnetics Research C, vol. 21, pp. 33-44, 2011.

[9] J. Cao, X. Zhao, C. Liu, L. Yan A, "Planar Compact Triple-Band Monopole Antenna For WLAN/WIMAX Applications", Progress In Electromagnetics Research Letters, Vol. 29, pp. 15-23, 2012.

[10] C. Y. Pan, T. S. Horng, W. S. Chen, C. H. Huang, "Dual Wideband Printed Monopole Antenna for WLAN/WiMAX Applications", IEEE Antennas Wireless Propagation Letters, vol. 6, pp. 149-151, 2007.

[11] I. Zahraoui, J. Zbitou, A. Errkik, E. Abdelmounim, A. M. Sanchez, "A Novel Printed Multiband Low Cost Antenna for WLAN and WiMAX Applications", International Journal of Microwave and Optical Technology (IJMOT), vol. 11, pp. 137-144, 2016.

[12] S. S. lodhi, P.K. Singhal, V.V. Thakare, "Design and Analysis of Tripple Band Koch Fractal Yagi Uda Antenna", International Journal of Electrical and Computer Engineering (IJECE), vol. 3, no. 4, August 2013, pp. 456-460.

[13] K. K. Parashar, "Design and Analysis of I-Slotted Rectangular Microstrip Patch Antenna for Wireless Application", International Journal of Electrical and Computer Engineering (IJECE), vol. 4, no. 1, Feburary 2014, pp. 31-36.

[14] Yi Huang University of Liverpool UK, Kevin Boyle NXP Semiconductors, UK, Book of Antennas from theory to practice (John Wiley \& Sons Ltd, 2008).

[15] J. X. Liu, W. Y. Yin, S. L. He, "A new Defected Ground Structure and its Application for Miniaturized Switchable Antenna”, Progress in Electromagnetic Research, vol. 107, pp. 115-128, 2010.

[16] I. Zahraoui, A. Errkik, J. Zbitou, E. Abdelmounim, A. M. Sanchez, "A New Design of a Microstrip Antenna With Modified Ground for DCS and WiMAX Applications", International Journal of Microwave and Optical Technology (IJMOT), vol.11, pp. 237-244, 2016.

[17] Y. J. Sung, M. Kim, Y.-S. Kim, "Harmonics Reduction with Defected Ground Structure for a Microstrip Patch Antenna", IEEE Antennas and Wireless Propagation Letters, vol. 2, 2003.

[18] Chul-Soo, Jun-Seok Park, Dal Ahn, Jae-Bong Lim, "A Novel 1-D Periodic Defected Ground Structure for Planar Circuits", IEEE Microwave and Guided Wave Letters, vol. 10, no. 4, 2000.

[19] A. Roy, P. K. Choudhary, S. Anand, P. P. Sarkar and S. Bhunia, "A Novel Approach on Miniturization of Microstrip Patch Antenna with Loaded Strip", Elictronic, Communication and Instrumentation (ICECI), International Conference on, IEEE. pp. 1-4, 2014.

[20] M. N. Suma, "Investigations on Broadband Planar Monopole Antennas with Truncated Ground Plane", Department Of Electronics Faculty of Technology Technology Cochin University of Science and Cochin-22 India, Jan 2008.

[21] H. -M. Hsiao, J. W. Wu, Y. D. Wang, J. -H Lu,S. -H. Chang, "Novel dual-Broadband Rectangular-Slot Antenna for 2.4/5-GHz Wireless Communication", Microwave Optical Technology Letters, 46: 197-201, 2005.

[22] Su, Chih-Ming, et al., "Dual-band Slot Antenna for 2.4/5.2 GHz WLAN Operation", Microwave and Optical Technology Letters, 35: 306-308, 2002.

[23] J. W. Wu, Y. D. Wang, H. M. Hsiao, J. H. Lu, "T-shaped Monopole Antenna with shorted L Shaped Strip-Sleeves for WLAN 2.4/5.8 GHz Operation”, Microwave Optical Technology Letters, vol. 46, no. 1, 65-69, 2005.

\section{BIOGRAPHIES OF AUTHORS}

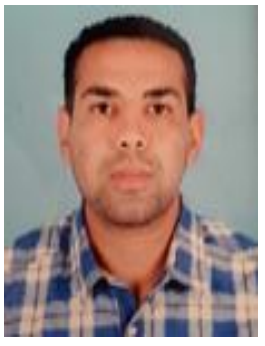

Issam Zahraoui was born in Oued Zem, Morocco, In 6 April 1984. He received the Master degree in science of networks and telecommunications from the Faculty of Sciences in El jadida Morocco. $\mathrm{He}$ is currently working toward the Ph.D. degree in communication engineering at Faculty of Sciences and Techniques, University Hassan 1st in Settat, Morocco. He is involved in the design of microwave hybrid circuits and antennas. 


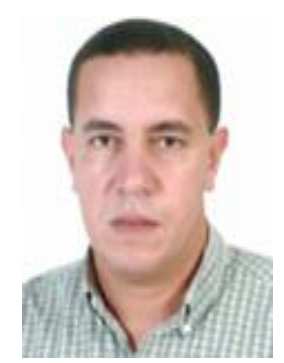

Ahmed Errkik was born in July 1960 in Morocco. He received the Ph.D. degree in physics from the University of Technology Compiègne (UTC), Compiègne, France. He is currently an associate Professor of physics in FST University Hassan 1st, Settat, Morocco, and he is the head of the laboratory LMEET. He is involved in the design of hybrid, monolithic active and passive microwave electronic circuits.

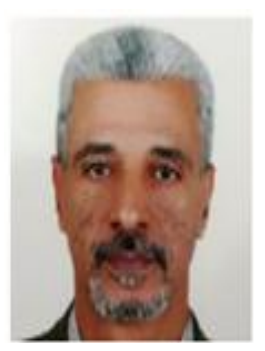

Abdelali Tajmouati was born in, Morocco, in 1962. He received the Ph.D. degree in science engineering from the University of Perpignan, France, in 1992. He is currently an associate Professor of Electronics, thermal transfer and termodynamic in faculty of sciences and techniques University Hassan 1st, Settat,, Morocco. He is involved in the design of hybrid, monolithic active and passive microwave electronic circuits.

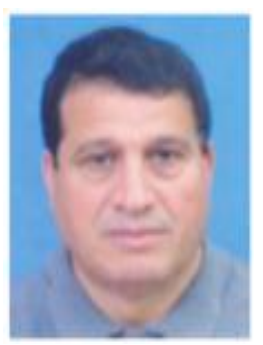

Larbi El Abdellaoui was born in Tiflet, Morocco, in 1961. He received the Ph.D. degree in electronics from the University of Metz, in 1994, France. He is currently an associate Professor of physics in Faculty of Sciences and Techniques, University Hassan 1st, Settat, Morocco. He is involved in the design of hybrid, monolithic active and passive microwave electronic circuits.

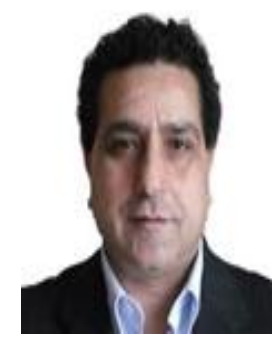

Mohamed Latrach was born in Douar Ksiba, Sless, Morocco, in 1958. He received the Ph.D. degree in electronics from the University of Limoges, Limoges, France, in 1990. He is currently a Professor of microwave engineering with the Ecole Suprieure d'Electronique de l'Ouest (ESEO), Angers, France, where his research involves RF and microwaves. His field of interest is the design of hybrid, monolithic active, and passive microwave circuits, metamaterials, LH materials, antennas and their applications in wireless communications, and wireless power transmission. 